\title{
Direct identification of Photobacterium damselae subspecies piscicida by PCR-RFLP analysis
}

\author{
V. Zappulli ${ }^{1}$, T. Patarnello ${ }^{1,2}$, P. Patarnello ${ }^{1}$, F. Frassineti ${ }^{1}$, R. Franch ${ }^{1,2}$, A. Manfrin ${ }^{3}$, \\ M. Castagnaro ${ }^{1}$, L. Bargelloni ${ }^{1, *}$ \\ ${ }^{1}$ Dipartimento di Sanità Pubblica, Patologia Comparata e Igiene Veterinaria - Agripolis, Università di Padova, \\ Viale dell'Università 16, 35020 Legnaro, Italy \\ ${ }^{2}$ Dipartimento di Biologia, Università di Padova, Via Ugo Bassi 58/B, 35131 Padova, Italy \\ ${ }^{3}$ Istituto Zooprofilattico Sperimentale delle Venezie, Viale dell'Università, 35020 Legnaro, Italy
}

\begin{abstract}
Fish pasteurellosis is an infectious disease that affects several teleost species living in temperate marine waters. The pathogen responsible, Photobacterium damselae subspecies piscicida, shows high genetic similarity with $P$. damselae subsp. damselae, making subspecies discrimination extremely laborious. Here we report for the first time a PCR-RFLP method for the identification of $P$. damselae subsp. piscicida without prior isolation in pure culture. Genomic sequence information was obtained through cloning and sequencing of RAPD products. Two P. damselae-specific primer pairs were developed and tested on 17 strains of $P$. damselae subsp. piscicida, 10 strains of $P$. damselae subsp. damselae, and 6 closely related control species. High sensitivity was achieved in PCR amplification on serially diluted samples ( $<180 \mathrm{fg}$ of pure bacterial DNA or $<10 \mathrm{fg}$, depending on the amplified fragment). Restriction analysis of PCR products showed a unique digestion profile for all P. damselae subsp. piscicida strains. The same PCR-RFLP method was implemented on total DNA samples extracted from experimentally infected sea bream and sea bass. Positive results were obtained on fish with clear signs of the disease as well as on challenged, but asymptomatic, fish. The method presented here might provide a useful tool for both prevention and rapid diagnosis of fish pasteurellosis.
\end{abstract}

KEY WORDS: Photobacterium damselae subsp. piscicida - Fish pasteurellosis - PCR-RFLP . Diagnostic tool

\section{INTRODUCTION}

Fish pasteurellosis is an infectious disease that affects several teleost species living in temperate marine waters (Magariños et al. 1996). The responsible pathogen, Photobacterium damselae subspecies piscicida, was firstly isolated in North America in 1963 (Snieszko 1964). Since then it has been reported to cause severe outbreaks in farmed marine fish in Japan and the Mediterranean area. The etiological agent of the disease has been assigned to the genus Photobacterium (Family Vibrionaceae) as a separate subspecies (subsp. piscicida) than P. damselae subsp. damselae. High genetic similarity was found between the 2 subspecies by DNA-DNA hybridization and 16S rRNA gene sequencing (Gauthier et al. 1995, Osorio et al. 1999), despite the fact that they show distinctive biochemical and morphological characteristics (Magariños et al. 1992, Thyssen et al. 1998). Both subspecies are considered pathogenic for marine fish. However, only subspecies piscicida causes acute infections with high mortality rates. The role of $P$. damselae subsp. damselae as a fish pathogen is not clear because it is often isolated in healthy fish (Botella et al. 2002, Pujalte et al. 2003). Therefore, the ability to detect very low quantities of the micro-organism directly in fish tissues and in water or sediment samples, as well as to discriminate between the 2 subspecies, is necessary for 
a better prevention of the disease through control of the presence of the pathogen in the water and/or carrier fishes. Thus far, a broad variety of methods has been evaluated for highly sensitive, species-(subspecies) identification of the pathogen without prior isolation as pure culture. Tested methods include enzyme-linked immunosorbent assays (ELISA) and enzyme immuno-assay (EIA) techniques (Bakopoulos et al. 1997, Romalde et al. 1999), plasmid DNA PCR (Aoki et al. 1997), 16S rRNA gene sequencing (Osorio et al. 1999), and primers designed following random amplified polymorphic DNA (RAPD) (Dalla Valle et al. 2002). All these methods, however, could not reliably discriminate between the 2 subspecies. A method based on duplex PCR of ureC and 16S rRNA genes was proposed by Osorio et al. (2000), due to the lack of the ureC gene in the subspecies piscicida, but subspecies discrimination was based on indirect evidence (lack of amplification of ureC). Lately, a combined approach of PCR technique and plating method has been proposed (Rajan et al. 2003). Other methods such as ribotyping (Magariños et al. 1997), RAPD (Random Amplified Polymorphic DNA) (Magariños et al. 2000), and amplified fragment length polymorphism (AFLP) (Thyssen et al. 2000, Kvitt et al. 2002, L. Bargelloni unpubl. data) showed the ability to differentiate the 2 subspecies as well as to identify clusters of $P$. damselae subsp. piscicida strains. However, these methods require DNA extraction from pure cultures and reference profiles are needed for strain identification.

In the present study, we describe a highly sensitive test based on PCRRFLP analysis that allows culture-independent discrimination between the 2 subspecies.

\section{MATERIALS AND METHODS}

Bacterial cultures and DNA extraction. A total of 17 strains of Photobacterium damselae subsp. piscicida and 10 strains of $P$. damselae subsp. damselae were examined in the present study, including type and reference strains for both subspecies (Table 1). Among the 10 strains of $P$. damselae subsp. damselae, 3 strains formerly classified as $P$. histaminum were included. Based on the results

Table 1. Bacterial strains included in the study of Photobacterium damselae subsp. piscicida and P. damselae subsp. damselae. NR: host species not reported

\begin{tabular}{|c|c|c|}
\hline Strain & Origin & Source \\
\hline \multicolumn{3}{|c|}{ P. damselae subsp. piscicida } \\
\hline NCIMB $2058^{\mathrm{T}}$ & Japan & Yellowtail Seriola quinqueradiata \\
\hline ATCC 17911 & USA & White perch Roccus americanus \\
\hline I736 & Italy & Sea bass Dicentrarchus labrax \\
\hline $\mathrm{K} 12$ & Italy & Sea bass Dicentrarchus labrax \\
\hline OO4 & Italy & Sea bass Dicentrarchus labrax \\
\hline PD010099 & Italy & Sea bass Dicentrarchus labrax \\
\hline PD010701 & Italy & Sea bream Sparus aurata \\
\hline PN510 & Greece & Sea bream Sparus aurata \\
\hline K5 & Greece & Sea bass Dicentrarchus labrax \\
\hline B3 & Greece & Sea bass Dicentrarchus labrax \\
\hline B7 & Greece & Sea bass Dicentrarchus labrax \\
\hline SU7 & Greece & Sea bass Dicentrarchus labrax \\
\hline M28561 & Japan & Yellowtail Seriola quinqueradiata \\
\hline TFP88012 & Japan & Yellowtail Seriola quinqueradiata \\
\hline SP98037 & Japan & Yellowtail Seriola quinqueradiata \\
\hline SA071194 & Israel & Sea bream Sparus aurata \\
\hline XXX000696 & Israel & Hybrid striped bass \\
\hline 249/Ittio99 & Italy & Sea bass Dicentrarchus labrax \\
\hline 332/Ittio01 & Italy & Sea bass Dicentrarchus labrax \\
\hline 349/Ittio00 & Italy & Sea bass Dicentrarchus labrax \\
\hline D121 & Portugal & Sea bream Sparus aurata \\
\hline \multicolumn{3}{|c|}{ P. damselae subsp. damselae } \\
\hline ATCC $33539^{\mathrm{T}}$ & USA & Damselfish Chromis punctipinnis \\
\hline ATCC 35083 & USA & Brown shark Carcharhinus plumbeus \\
\hline NCIMB 2181 & USA & Sea water \\
\hline NCIMB 2182 & USA & Human leg wound \\
\hline NCIMB 2183 & USA & Human leg wound \\
\hline JCM $8967^{\mathrm{a}}$ & Japan & Sea water \\
\hline JCM 8969a & Japan & Sea water \\
\hline NCTC 11646 & UK & Human leg wound \\
\hline NCTC 11648 & UK & NR \\
\hline NCIMB $13351^{\mathrm{a}}$ & Japan & Sea water \\
\hline \multicolumn{3}{|l|}{ External controls } \\
\hline $\begin{array}{l}\text { Photobacterium } \\
\text { leiognathi } \\
(\text { CCUG 16229 })\end{array}$ & Malaysia & Teleost fish Leiognathus equula \\
\hline $\begin{array}{l}\text { P. phosphoreum } \\
\left(\text { NCIMB } 1282^{\mathrm{T}}\right)\end{array}$ & NR & NR \\
\hline $\begin{array}{l}\text { P. fischeri } \\
\left(\text { ATCC } 7744^{\mathrm{T}}\right)\end{array}$ & USA & NR \\
\hline $\begin{array}{l}\text { Vibrio hollisae } \\
\left(\text { NCTC } 11640^{\mathrm{T}}\right)\end{array}$ & USA & Human faeces \\
\hline $\begin{array}{l}V . \text { natriegens } \\
\left(\text { ATCC } 14048^{\mathrm{T}} \text { ) }\right.\end{array}$ & USA & Marine sediment \\
\hline $\begin{array}{l}\text { V. carchariae } \\
\text { (CCUG 19116) }\end{array}$ & USA & Brown shark Carcharhinus plumbeus \\
\hline $\begin{array}{l}V . \text { anguillarum } \\
5894 / 83\end{array}$ & UK & NR \\
\hline
\end{tabular}


of Kimura et al. (2000), P. histaminum has been now reclassified as $P$. damselae subsp. damselae. Negative controls were other Photobacterium species as well as selected marine Vibrio species, as listed in Table 1. Standard microbiological procedures were applied to obtain pure cultures for each strain. Total bacterial DNA was extracted from pure cultures using a DNeasy tissue kit (Qiagen) following the manufacturer's instructions. Extracted DNA was run on 1\% agarose gel to check for quality, and concentration was estimated using a UV spectrophotometer. A similar procedure was used to extract total genomic DNA from 5 to $15 \mathrm{mg}$ of fish tissue. These samples were collected in the course of a challenge experiment (see below).

Experimental infections. European sea bass (60 individuals) of $10 \mathrm{~g}$ body weight and gilthead sea bream (150 individuals) of $0.5 \mathrm{~g}$ body weight were used in 2 separate experiments of controlled infection. All fishes were obtained from the fish farm 'Valle Ca' Zuliani' (Pila di Porto Tolle, Rovigo, Italy). Fishes were transferred to the Istituto Zooprofilattico Sperimentale delle Venezie (IZSV, Legnaro, Italy) and kept in aerated and recirculated seawater at $20^{\circ} \mathrm{C}$ for $1 \mathrm{wk}$ for acclimation. Ten individuals for each species were sacrificed before starting the challenge. Gills, kidney, spleen, and liver were dissected from each specimen and stored in $80 \%$ ethanol at $4^{\circ} \mathrm{C}$ for subsequent analysis.

Sea bass were divided in 5 groups of 10 individuals each. All individuals were subjected to intraperitoneal injection with $0.1 \mathrm{ml}$ of a suspension of Photobacterium damselae subsp. piscicida $\left(10^{7}\right.$ bacteria $\left.\mathrm{l}^{-1}\right)$. For each group a different strain was used: Strain NCIMB 2058 ${ }^{\mathrm{T}}$ (Group Ba1), Strain 249/Ittio99 (Group Ba2), Strain 349/ Ittio00 (Group Ba3), Strain 332/Ittio01 (Group Ba4) (strains are listed in Table 1). The latter 3 strains were isolated and characterized at the IZSV from infection outbreaks in different fish farms. A fifth group (Ba5) was injected with $0.1 \mathrm{ml}$ of sterile water, and kept in the same tank with individuals of Group Ba4, separated by a metal grid (cohabitation group). Mortality was monitored $5 \mathrm{~d}$ after challenge, dead fish were removed and tissue samples collected as described above. Starting from Day 2 after challenge, 2 live individuals per group were removed every day if no mortality was observed. Tissue samples from these fish were collected and stored as described previously.

Sea bream were divided in 3 groups. Individuals of 2 groups (Br1 and $\mathrm{Br} 2$ ) were challenged by immersion for $30 \mathrm{~min}$ in $10 \mathrm{l}$ of aerated seawater with Photobacterium damselae subsp. piscicida $\left(3 \times 10^{6}\right.$ bacteria $\left.\mathrm{l}^{-1}\right)$. Group Br1 was challenged with Strain D121 (Osorio et al. 1999), Group Br2 with Strain 249/Ittio99 (see above). A third group (Br3) was mock-infected by immersion for $30 \mathrm{~min}$ in $10 \mathrm{l}$ of clean aerated seawater. Mortality was monitored for $15 \mathrm{~d}$ after challenge, dead fish were removed and tissue samples collected as described above. Starting from Day 2 after challenge, 2 to 5 live individuals per group were also removed every day if no mortality was observed. Tissue samples from these fish were collected and stored as described.

Amplification and cloning of RAPD PCR-products. RAPD was carried out on 8 Photobacterium damselae subsp. piscicida strains (ATCC17911; I736; PN510; M28561; K5; SA040296; SA071194; TFP88012) and 2 P. damselae subsp. damselae strains (ATCC35083; NCIMB2184). Two 10-mer primers (Operon 10-mer Kit A, Operon [now Qiagen]) were used: OPA-04 (AATCGGGCTG) and OPA-07 (GAAACGGGTG). The PCR reaction was carried out following a protocol modified by Grayson et al. (1999). A final volume of $25 \mu \mathrm{l}$ RAPD reaction mixture contained 0.5 units of Taq DNA polymerase (Promega), $1 \times$ thermophilic DNA polymerase buffer, magnesium free, $1.5 \mathrm{mM} \mathrm{MgCl}_{2}$, $0.2 \mathrm{mM}$ dNTPs, $12 \mathrm{pmol}$ (picomol) of primer and approximately 50 to $100 \mathrm{ng}$ of DNA. The thermal profile, carried out in a GeneAmp 9700 (Applied Biosystems), included a pre-denaturation step (2 min at $94^{\circ} \mathrm{C}$ ), plus 40 cycles consisting of $1 \mathrm{~min}$ at $94^{\circ} \mathrm{C}, 1 \mathrm{~min}$ at $36^{\circ} \mathrm{C}, 2 \mathrm{~min}$ at $72^{\circ} \mathrm{C}$. All the amplified products were analyzed on $1.8 \%$ agarose gel, visualized with ethidium bromide under UV light. Gel pictures were obtained with an Image Master ${ }^{\circledR}$ VDS, Fujifilm Thermal Imaging System FTI 500.

RAPD products were cloned into a plasmid vector (pCR-II, Invitrogen) using a commercial kit (TOPO-TA Cloning, Invitrogen), following the manufacturer's instructions. In each ligation reaction, $2 \mu \mathrm{l}$ of amplified DNA was used for each of the following RAPD amplifications: Strains I736 and ATCC35083 with Primer OPA-04; Strains 1736 and M28561 with Primer OPA-07. Insert size of recombinant clones (35 distinct colonies) was assessed by PCR using vector primers. Plasmids containing each of 6 inserts differing in size were prepared using a commercial kit (QIAprep Spin Miniprep Kit, Qiagen) and cycle-sequenced on both strands with vector universal primers in a $3700 \mathrm{ABI}$ sequencer.

The nucleotide sequences obtained were used as a query to search the GenBank section of complete bacterial genomes (www.ncbi.nlm.nih.gov/cgi-bin/ Entrez/genom_table_cgi) using the program BLAST with default settings, either with the BlastN or the TblastX option. Specific primers for 2 genomic regions (Table 2) were developed using the program Primer3 (http://www-genome.wi.mit.edu/cgi-bin/primer/ primer3_www.cgi).

Photobacterium damselae-specific PCR amplification. PCR amplifications using the primers listed in Table 2 were carried out under the following conditions: a final volume of $20 \mu \mathrm{l}$ PCR mixture contained 0.5 U of Taq DNA Polymerase (Promega), $1 \times$ thermo- 
Table 2. Primers used in the present study. Ta: annealing temperature

\begin{tabular}{|llc}
\hline Primer name & 5'-3' sequence & Ta $\left({ }^{\circ} \mathrm{C}\right)$ \\
\hline P.dam-5a_F & CAACCCTGCAACATTTCTACCAAG & 55 \\
P.dam-5a_R & GGAGTGCATGCCGAACAAGC & 55 \\
P.dam-1a_F & CTTAACGCTACGTGGTGACAGTT & 55 \\
P.dam-1a_R & AGACGATCGCCTGCAATAAC & 55 \\
\hline
\end{tabular}

philic DNA polymerase buffer, magnesium free, 1.5 $\mathrm{mM} \mathrm{MgCl} 2,0.2 \mathrm{mM}$ dNTPs, 10 pmol of each primer and approximately 50 to $100 \mathrm{ng}$ of bacterial DNA. The thermal profile included a predenaturation step (2 min at $94^{\circ} \mathrm{C}$ ), plus 30 cycles consisting of $45 \mathrm{~s}$ at $94^{\circ} \mathrm{C}, 45 \mathrm{~s}$ at $55^{\circ} \mathrm{C}$ and $1 \mathrm{~min}$ at $72^{\circ} \mathrm{C}$. DNA extracted from all strains listed in Table 1 were subjected to PCR amplification with primer pairs P.dam-5a_F-R and P.dam1a_F-R. Undiluted DNA extracted from fish tissues was amplified using similar PCR conditions, except for the number of cycles which was increased to 40 . PCR products were analyzed by gel electrophoresis as previously described.

The sensitivity of both PCR amplifications was assessed as follows: 1:10 serial dilutions of bacterial DNA were prepared from DNA stock solutions adjusted to $180 \mathrm{ng}$ DNA $\mu \mathrm{l}^{-1}$ (amplification with primer pair P.dam-5a_F-R) or $50 \mathrm{ng} \mathrm{\mu l}^{-1}$ (amplification with primer pair P.dam-1a_F-R) of Photobacterium damselae subsp. piscicida Strain NCIMB $2058^{\mathrm{T}}$ and $P$. damselae subsp. damselae Strain ATCC $33539^{\mathrm{T}}$. The concentration of amplified DNA ranged from $0.9 \mu \mathrm{g} \mathrm{DNA} \mathrm{ml}{ }^{-1}$ to $0.9 \mathrm{fg}$ DNA $\mu \mathrm{l}^{-1}$ (primer pair P.dam-5a_F-R) or from $0.5 \mathrm{ng}$ DNA $\mu \mathrm{l}^{-1}$ to $0.5 \mathrm{fg} \mathrm{DNA} \mu \mathrm{l}^{-1}$ (primer pair P.dam1a_F-R). Two $\mu$ of each dilution was used for PCR amplification. The amplification protocol was the same as described above, except for the number of cycles, which was increased to 45 .

Restriction fragment length polymorphism (RFLP) analysis. RFLP was carried out on DNA fragments amplified with primer pairs P.dam-5a_F-R and P.dam1a_F-R. All restriction enzymes and buffers were purchased from New England Biolabs (Beverly). Fragment P.dam-5a_F-R was serially digested with 4 restriction enzymes. Five to $10 \mu \mathrm{l}$ of each amplified DNA, depending on intensity of PCR products, were used for restriction. The reaction mixture had a final volume of $30 \mu \mathrm{l}$ containing $1.8 \mathrm{U}$ of Hha $I$ and $2 \mathrm{U}$ of ECoR $V, 1 \times$ NEBuffer 3 and $100 \mu \mathrm{g}$ bovine serum albumin $\mathrm{ml}^{-1}$. The reaction mixture was incubated at $37^{\circ} \mathrm{C}$ for $90 \mathrm{~min}$. Subsequently, to each sample was added $5 \mu$ of a solution containing $1 \mathrm{U}$ of BsmA I and $1 \times$ NEBuffer 3 . The reaction was then incubated for $60 \mathrm{~min}$ at $55^{\circ} \mathrm{C}$. Finally, $5 \mu$ l of a solution containing $2 \mathrm{U}$ of Bsr I and $1 \times$ NEBuffer 3 was added, and the reaction was incubated at $65^{\circ} \mathrm{C}$ for $60 \mathrm{~min}$. Fragment P.dam-1a_F-R was digested with a single restriction enzyme under the following conditions: as above, 5 to $10 \mu \mathrm{l}$ of amplified DNA was used in a $30 \mu$ reaction mixture containing $3 \mathrm{U}$ of BstU I and $1 \times$ NEBuffer 2. The reaction was incubated at $60^{\circ} \mathrm{C}$ for $90 \mathrm{~min}$.

Restriction fragments were separated by electrophoresis on $4 \%$ agarose obtained mixing 3 parts of NuSieve ${ }^{\circledR}$ agarose (FMC Bioproducts [now Cambrex]) with 1 part of normal agarose. Restriction fragments were visualized and documented as described previously.

\section{RESULTS}

Six RAPD fragments were cloned and sequenced (GenBank AY191120, AY191121, AY332620AY332623). Similarity searches against bacterial nucleotide sequence databases identified 5 out of these 6 selected regions as putative homologues of genomic sequences from Vibrio cholerae (Strain N16961). On the basis of the alignment with these sequences, specific primers (P.dam-5a_F-R, P.dam1a_F-R, Table 2) were designed on non-conserved sites of 2 genomic regions (GenBank AY191120, AY191121). The expected size of the amplification products, P.dam-5a_F-R and P.dam-1a_F-R, were 713 and 201 base pairs (bp), respectively. The use of these newly designed primers in PCR amplification produced a visible product of correct size for all strains of Photobacterium damselae subsp. piscicida and $P$. damselae subsp. damselae, including the 3 strains (JCM8967, JCM8969, NCIMB13351) formerly classified as $P$. histaminum. No amplification product was obtained from external controls using either primer pair. External controls included closely related species such as $P$. leiognathi, $P$. fisheri, and $P$. phosphoreum. These results indicate that amplifications using either primer pair are highly specific to $P$. damselae.

The sensitivity of amplification was assessed on 1:10 serial dilutions of pure bacterial DNA. PCR amplification with primer pair P.dam-5a_F-R showed that the minimum detectable amount of Photobacterium damselae DNA was between $1.8 \mathrm{pg}$ and $180 \mathrm{fg}$ (Fig. 1A). Higher sensitivity was achieved with primer pair P.dam-1a_F-R. In this case the lowest amount of DNA producing a visible product was 1 to $10 \mathrm{fg}$ (Fig. 1B). Neither amplification with primer pair P.dam-5a_F-R nor with P.dam-1a_F-R, however, could discriminate between $P$. damselae subsp. piscicida and $P$. damselae subsp. damselae. To achieve subspecies identification, a restriction analysis was carried out on both amplified fragments. Four restriction enzymes (Hha I, Bsr I, EcoR V, BsmA I) were used for multiple 


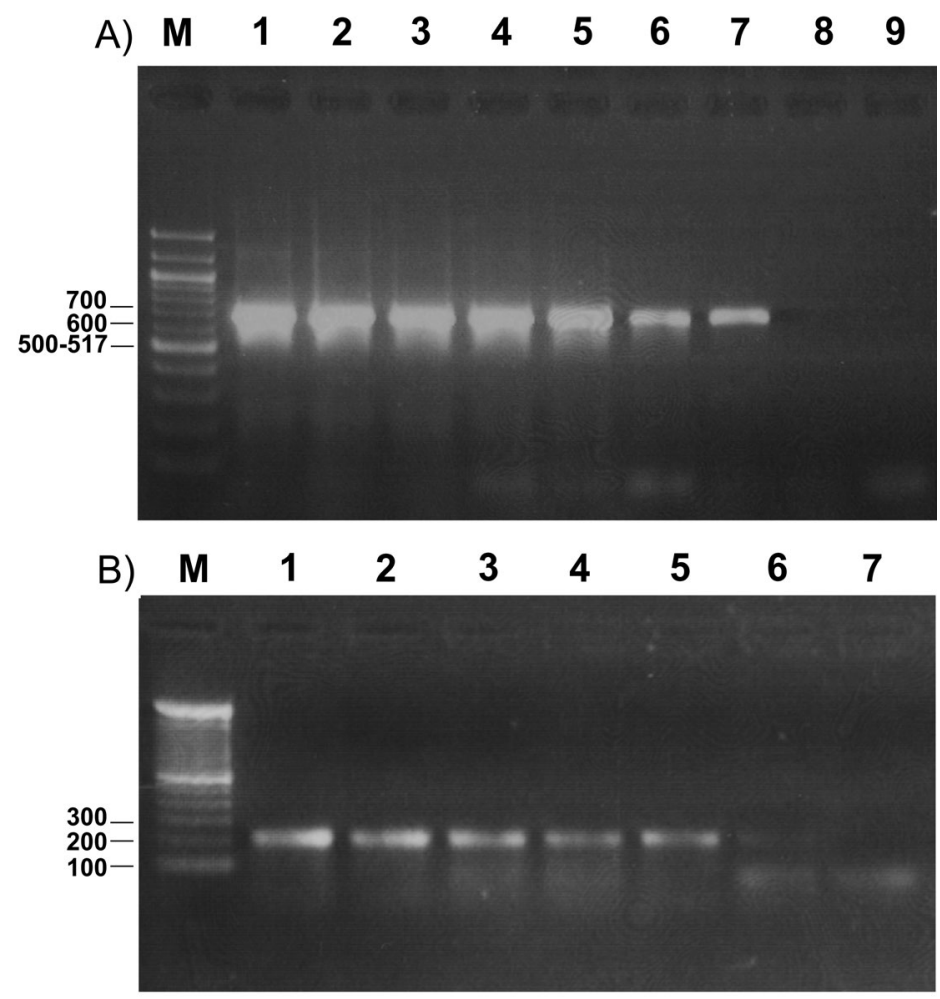

Fig. 1. Sensitivity of PCR amplification with Photobacterium damselae-specific primers. (A) Agarose gel electrophoresis of PCR products using primer set P.dam-5a_F-R. Lane M: sizemarker 100 bp DNA ladder (New England Biolabs); Lanes 1 to 9 are serial dilutions (1:10) of purified DNA of $P$. damselae subsp. piscicida strain ATCC 17911 used as template:

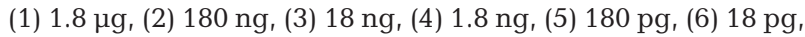
(7) 1.8 pg, (8) 180 fg, (9) 18 fg. (B) Agarose gel electrophoresis of PCR products using primer set P.dam-1a_F-R. Lane M: size-marker 100 bp DNA ladder (Invitrogen); Lanes 1 to 7 are serial dilutions (1:10) of purified DNA of $P$. damselae subsp. piscicida strain NCIMB $2058^{\mathrm{T}}$ used as template: (1) $1 \mathrm{ng}$,

(2) 100 pg (3) 10 pg, (4) 1 pg, (5) 100 fg, (6) 10 fg, (7) 1 fg

Table 3. Restriction analysis of fragment P.dam-5a_F-R

\begin{tabular}{|c|c|c|}
\hline Strain(s) & Enzymes & $\begin{array}{l}\text { Expected fragments } \\
\text { (size in bp) }\end{array}$ \\
\hline $\begin{array}{l}\text { All Photobacterium damselae } \\
\text { subsp. piscicida strains }\end{array}$ & $E \operatorname{coR} V, B s m A I$ & $459,158,63,33$ \\
\hline $\begin{array}{l}\text { P. damselae } \\
\text { subsp. damselae strains } \\
\text { ATCC } 33539^{\mathrm{T}}, \text { NCIMB2181, } \\
\text { JCM8967, NCTC11646, } \\
\text { NCIMB13351 }\end{array}$ & Hha I, BsmA I & $310,182,158,63$ \\
\hline $\begin{array}{l}\text { P. damselae subsp. } \\
\text { damselae strain } \\
\text { JCM8969 }\end{array}$ & ECoR $V, B s r I$ & $351,221,108,33$ \\
\hline $\begin{array}{l}\text { P. damselae subsp. } \\
\text { damselae strains } \\
\text { ATCC35083, NCIMB2182, } \\
\text { NCIMB2183, NCTC11648 }\end{array}$ & $\begin{array}{c}\text { Hha } I, B s r I \\
\text { ECoR } V, B s m A I\end{array}$ & $\begin{array}{l}310,158,108,63 \\
41,33\end{array}$ \\
\hline
\end{tabular}

digestion of fragment P.dam-5a_F-R. Four different restriction profiles were obtained depending on the strain analyzed (Table 3). A single digestion pattern was observed for all 17 strains of $P$. damselae subsp. piscicida (Fig. 2, Lane 1). Three additional profiles characterized the examined strains of $P$. damselae subsp. damselae (Fig. 2, Lanes 2 to 4). Each amplified fragment was cut by at least 2 enzymes. The restriction pattern of all $P$. damselae subsp. piscicida strains could be clearly distinguished by the presence of a fragment larger than $400 \mathrm{bp}$ and the absence of a fragment of ca. 310 to $350 \mathrm{bp}$. In the restriction analysis of the amplified fragment P.dam-1a_F-R, a single enzyme $(B s t U I)$ was used. Only $1 B s t U$ I restriction site is present in DNA amplified from all the strains of $P$. damselae subsp. piscicida, whereas 2 restriction sites are found for all $P$. damselae subsp. damselae strains (Fig. 3, Table 4). The only exception is $P$. damselae subsp. damselae strain NCIMB2181, where only 1 restriction site is present, namely the one distinguishing all $P$. damselae subsp. damselae strains from all P. damselae subsp. piscicida (Fig. 3, Lane 2).

The PCR-RFLP method described above was then tested on DNA extracted from fish tissues that were collected during a challenge experiment on sea bream and sea bass (see 'Materials and methods'). After experimental infection, 3 sea bass groups (Ba2, Ba3 and $\mathrm{Ba} 4$ ) showed high mortality. Group Ba1, which was infected with Reference Strain NCIMB2058 ${ }^{\mathrm{T}}$, and Group Ba5, which was maintained in cohabitation with individuals of Group Ba4, displayed no mortality after 1 wk. Therefore, for Groups Ba1 and Ba5, tissue samples were collected only from fish that were still alive and subsequently sacrificed. For Groups Ba2, Ba3 and Ba4, deceased fish were also analyzed. Similarly, in the sea bream experiment, only Group Br2, which had been infected with Photobacterium damselae subsp. piscicida Strain 249/Ittio99, showed high mortality after 4 d post-challenge. No mortality was recorded after 15 d for Group Br1, which was challenged with the repeatedly-transferred Strain Dl21 (see 'Materials and methods'), nor for Group Br3 that included only mock-infected individuals. As in the sea bass experiment, only sacrificed animals were therefore analyzed for Groups Br1 and Br3. Spleen tissue samples of 2 or 3 randomly selected individuals per group were processed to extract total genomic DNA. Extracted DNA was subsequently used for PCR-amplification and restriction analysis of both fragments P.dam-5a_F-R and P.dam-1a_F-R. Two 


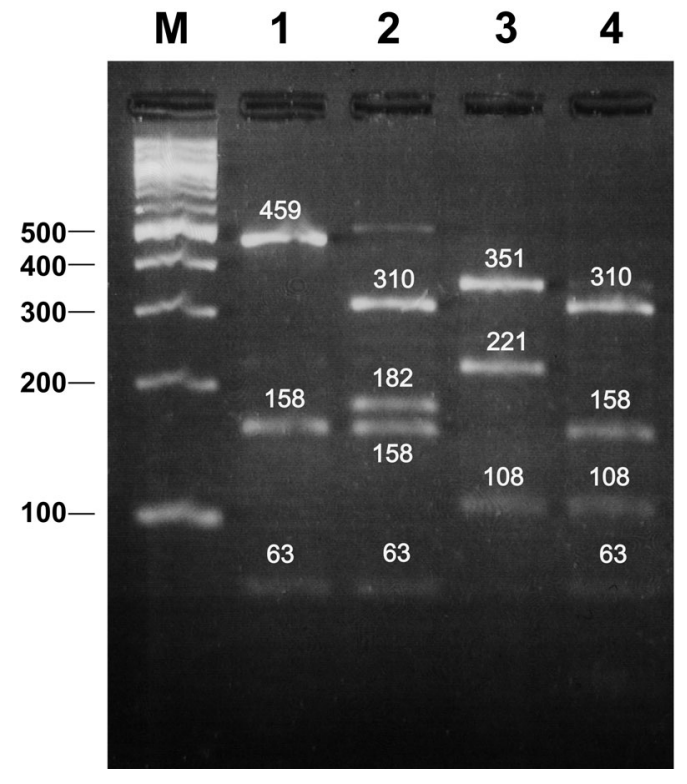

Fig. 2. RFLP analysis of Photobacterium damselae-specific PCR product P.dam-5a_F-R. Electrophoresis on 3:1 (Nusieve: normal) agarose gel of fragment P.dam-5a_F-R amplified on $P$. damselae subsp. piscicida and P. damselae subsp. damselae strains and digested with Hha I, Bsr I, ECoR V, and BsmA I. Lane M: size-marker 100 bp DNA ladder (Invitrogen); Lane 1: P. damselae subsp. piscicida Strain NCIMB 2058 ${ }^{\mathrm{T}}$; Lanes 2 to 4: P. damselae subsp. damselae Strains JCM 8967, JCM 8969, and NCTC 11648, respectively. Size of each restriction fragment is indicated

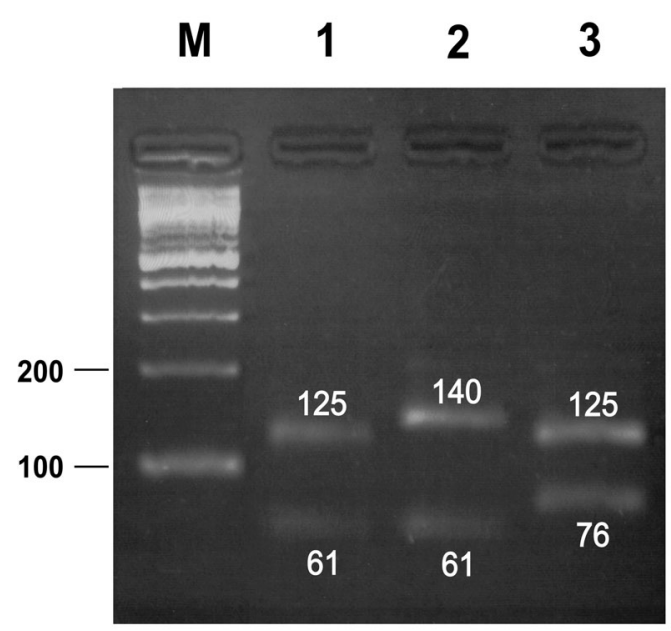

Fig. 3. RFLP analysis of Photobacterium damselae-specific PCR fragment P.dam-1a_F-R. Electrophoresis on 3:1 (Nusieve:normal) agarose gel of fragment P.dam-1a_F-R amplified on $P$. damselae subsp. piscicida and $P$. damselae subsp. damselae strains and digested with restriction enzyme $B s t U$ I. Lane M: size-marker 100 bp DNA ladder (Invitrogen); Lanes 1 to 3: $P$. damselae subsp. damselae Strains NCTC 11648, NCIMB 2181, and $P$. damselae subsp. piscicida Strain NCIMB $2058^{\mathrm{T}}$, respectively. Size of each restriction fragment is indicated sea bream and 2 sea bass individuals belonging to the group of fishes sacrificed before starting the challenge experiment (negative controls) were included in the analysis as well. Results of amplification from fish tissues are summarized in Table 5. An example of amplification products is presented in Fig. 4. A visible product was obtained from all individuals of sea bass Groups Ba2, Ba3 and Ba4 and of sea bream Group Br2, when analyzing fragment P.dam-1a_F-R. All these groups presented high mortality after infection. Similar results were obtained using the primer pair P.dam5a_F-R, except for 1 individual of sea bass Group Ba2 that was negative. The same individual showed a weak product for the shorter amplified fragment (Table 5). For sea bass Groups Ba1 and Ba5, and for sea bream Group Br1 only amplification with primer pair P.dam-1a_F-R yielded a faint, but detectable PCR product (Fig. 4). No amplified fragments were observed for sea bream Group Br3 (mock-infected animals) and for sea bass and sea bream negative controls. Amplified DNA from positive individuals was subsequently digested with the appropriate restriction enzyme(s). A single digestion pattern was obtained for each fragment, confirming the presence of $P$. damselae subsp. piscicida in the tissue samples examined. An example of the profiles obtained is presented in Fig. 5.

\section{DISCUSSION}

As already mentioned, in the last few years, several different molecular techniques have been evaluated in order to develop a highly sensitive test for discriminating the 2 highly genetically related subspecies of Photobacterium damselae. In the present study, we used cloning and sequencing of RAPD amplified fragments as a source of genomic sequence information. In fact, this approach provided a good starting point to develop specific primers. Dalla Valle et al. (2002) used a similar method to design primers that specifically amplified strains of both subspecies, although no discrimination between subspecies was achieved. In the present study, 2 pairs of specific primers were developed allowing amplification of all strains from both subspecies, without cross-amplification of external controls. Among the outgroup strains, the most closely related species to $P$. damselae and other common Vibrio species were included. This evidence indicates that amplification of both DNA fragments occurs with high specificity and sensitivity. In controlled conditions it was possible to detect very low amounts of bacterial DNA, with a limit of $1.8 \mathrm{pg}$ DNA for fragment P.dam-5a_F-R, and $10 \mathrm{fg}$ for fragment P.dam-1a_F-R. The sensitivity achieved in this work for fragment $P$. dam-5a_F-R was generally comparable to that obtained in previous studies for direct PCR detection of $P$. damse- 
Table 4. Restriction analysis of fragment P.dam-1a_F-R

\begin{tabular}{|lcc|}
\hline Strain(s) & $\begin{array}{c}\text { Restriction site(s) } \\
\text { for BstU I }\end{array}$ & $\begin{array}{c}\text { Expected fragments } \\
\text { (size in bp) }\end{array}$ \\
\hline $\begin{array}{l}\text { All Photobacterium damselae } \\
\text { subsp. piscicida strains }\end{array}$ & $124-128$ & 125,76 \\
$\begin{array}{l}\text { All P. damselae } \\
\text { subsp. damselae strains } \\
\text { except for NCIMB2181 }\end{array}$ & $124-128$ & $125,61,15$ \\
$\begin{array}{l}\text { P. damselae subsp. damselae } \\
\text { strain NCIMB2181 }\end{array}$ & $139-142$ & 140,61 \\
\hline
\end{tabular}

Table 5. PCR-RFLP analysis of fish tissues from challenge experiments. Under 'Sample' column, initial letters denote species: Dl represents Dicentrarchus labrax; Sa represents Sparus aurata. S and D in parentheses after sample code denote sacrificed and deceased individuals, respectively

\begin{tabular}{|c|c|c|c|}
\hline \multirow{2}{*}{$\begin{array}{l}\text { Experimental } \\
\text { group }\end{array}$} & \multirow{2}{*}{ Sample } & \multicolumn{2}{|c|}{$\longrightarrow$ Primers } \\
\hline & & P.dam-1a_F-R & P.dam-5a_F-R \\
\hline \multicolumn{4}{|c|}{ Sea bass Dicentrarchus labrax } \\
\hline Ba1 (Strain NCIMB 2058 ${ }^{\mathrm{T}}$ ) & Dl14a (S) & - & - \\
\hline Ba1 (Strain NCIMB $2058^{\mathrm{T}}$ ) & Dl31a (S) & $+/-$ & - \\
\hline Ba1 (Strain NCIMB 2058 ${ }^{\mathrm{T}}$ ) & Dl39a (S) & $+/-$ & - \\
\hline Ba2 (Strain 249/Ittio99) & Dl12b (S) & + & + \\
\hline Ba2 (Strain 249/Ittio99) & Dl29b (D) & + & + \\
\hline Ba2 (Strain 249/Ittio99) & Dl41b (D) & $+/-$ & - \\
\hline Ba3 (Strain 349/Ittio00) & Dl11c (S) & + & + \\
\hline Ba3 (Strain 349/Ittio00) & Dl32c (D) & + & + \\
\hline Ba3 (Strain 349/Ittio00) & Dl33c (D) & + & + \\
\hline Ba4 (Strain 332/Ittio01) & Dl10d (S) & + & + \\
\hline Ba4 (Strain 332/Ittio01) & Dl36d (D) & + & + \\
\hline Ba4 (Strain 332/Ittio01) & Dl37d (D) & + & + \\
\hline Ba5 (cohabitation) & Dl7e (S) & $+/-$ & - \\
\hline Ba5 (cohabitation) & Dl23e (S) & $+/-$ & - \\
\hline Negative control & $\mathrm{Dl3f}(\mathrm{S})$ & - & - \\
\hline Negative control & Dl5f (S) & - & - \\
\hline \multicolumn{4}{|l|}{ Sea bream Sparus aurata } \\
\hline Br1 (Strain D121) & Sa109 (S) & $+/-$ & - \\
\hline Br1 (Strain Dl21) & Sa111 (S) & $+/-$ & - \\
\hline Br2 (Strain 249/Ittio99) & Sa99 (S) & + & + \\
\hline Br2 (Strain 249/Ittio99) & Sa130 (D) & + & + \\
\hline Br2 (Strain 249/Ittio99) & Sa131 (D) & + & + \\
\hline Br3 (negative control) & Sa41 (S) & - & - \\
\hline Br3 (negative control) & $\mathrm{Sa} 45(\mathrm{~S})$ & - & - \\
\hline
\end{tabular}

lae (1 pg, Osorio et al. 1999; 350 fg, Kvitt et al. 2002), whereas the sensitivity for the amplification of fragment P.dam-1a_F-R is similar or slightly higher than the lowest detection limit reported to date $(20 \mathrm{fg}$, Dalla Valle et al. 2002). The higher sensitivity observed for fragment P.dam-1a_F-R is likely due to the smaller size of the amplified product.

Different estimates of the DNA content of single bacterial cells have been reported for $P$. damselae $(0.5 \mathrm{fg}$ per cell, Osorio et al. 1999; less than $10 \mathrm{fg}$ per cell, Kvitt et al. 2002). The DNA content in related species ranges between 4.5 and $7 \mathrm{fg}$ DNA per cell based on their genome size ( $V$. cholerae $4.03 \mathrm{Mbp}, V$. vulnificus
5.26 Mbp, P. profundum 6.4 Mbp). The DNA content of $P$. damselae is likely comparable to that of the abovementioned species, and similar to the value proposed by Kvitt et al. (2002; $<10 \mathrm{fg}$ per cell). If this holds true, the PCR method presented here allows the detection of less than 10 bacterial cells. This sensitivity is 3 orders of magnitude higher than the most sensitive immunological test that is presently in use for routine diagnosis of fish pasteurellosis (10 ${ }^{4}$ cells, Romalde et al. 1999).

The most important feature of the method proposed in the present work, however, is the ability to discriminate between Photobacterium damselae subsp. piscicida and P. damselae subsp. damselae. A unique restriction pattern for both amplified fragments was observed for all the P. damselae subsp. piscicida strains examined. Digestion profiles of all the $P$. damselae subsp. damselae strains could always be distinguished from the RFLP profile of $P$. damselae subsp. piscicida. None of the previously reported cultureindependent methods was suitable for subspecies identification. A partial exception is the $16 \mathrm{~S}$-ureC method proposed by Osorio et al. (2000), where lack of amplification of the ureC gene indicates the presence of $P$. damselae subsp. piscicida. Compared to the 16SureC method, the PCR-RFLP analysis proposed here represents a substantial improvement in terms of sensitivity and specificity. For instance, a distinctive RFLP pattern for $P$. damselae subsp. piscicida allows the detection of this subspecies even when $P$. damselae subsp. damselae is also present (data not shown). This cannot be obtained with the method proposed by Osorio et al. (2000), because lack of ureC amplification for $P$. damselae subsp. piscicida would be obscured by the presence of a PCR product from $P$. damselae subsp. damselae. This is an important issue because active and dormant states of the microorganism have been found to be present for both subspecies in the same environment, and in similar fish species (Fouz et al. 1998, Fouz et al. 2000, Botella et al. 2002). High sensitivity is obviously required to detect very low concentrations of the micro-organism, but subspecies discrimination is necessary as well, because of the biological differences between the 2 subspecies, 

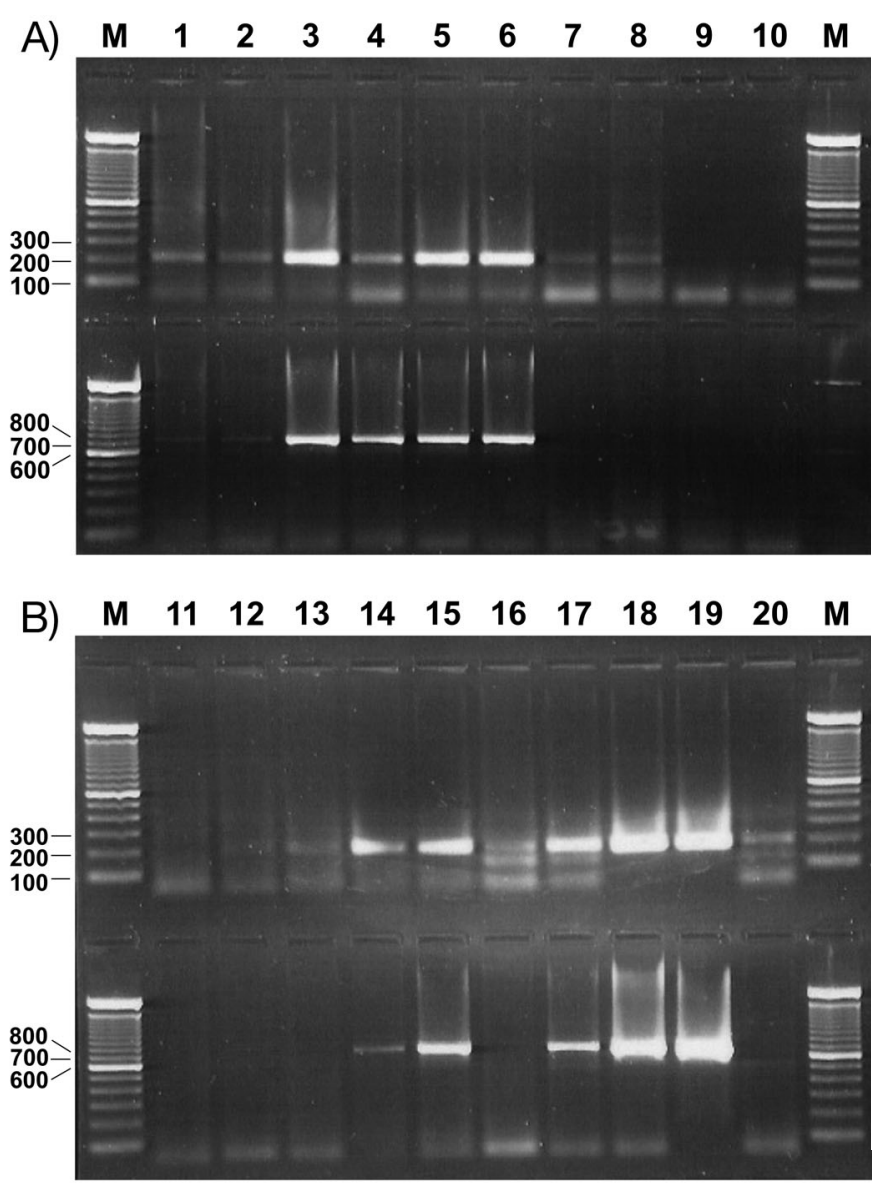

Fig. 4. PCR detection of Photobacterium damselae in tissues from experimentally infected fishes. Agarose gel electrophoresis of PCR products from DNA extracted from tissues using primer set P.dam-1a_F-R (A) and P. dam-5a_F-R (B). Lane M (A, B): size-marker 100 bp DNA ladder (Invitrogen); Lanes 1 to 20: Dl11c, Dl32c, Dl33c, Dl10d, Dl36d, Dl37d, Dl7e, Dl23e, Dl5f, Sa41, Dl14a, Dl31a, Dl39a, Dl12b, Dl29b, Dl41b, Sa99, Sa130, Sa131, and Sa109. See Table 5 for sample names

especially the diverse potential for pathogenicity. An additional feature of a rapid test should be the possibility of identifying the microorganism from fish tissue samples. To evaluate this aspect, the PCR-RFLP method was applied to tissue samples collected from fishes experimentally infected with different strains of P. damselae subsp. piscicida. Positive amplification of fragment P.dam-5a_FR was obtained only from those experimental groups of fish showing high mortality, where pathogen titre was likely very high. The use of primer pair P.dam-1a_F-R, however, allowed the amplification of bacterial-specific DNA fragments even from individuals that belonged to experimental groups showing no mortality. These groups had been either infected with low virulence strains or left in cohabitation with infected fish without direct challenge. Restriction analysis subsequently demonstrated

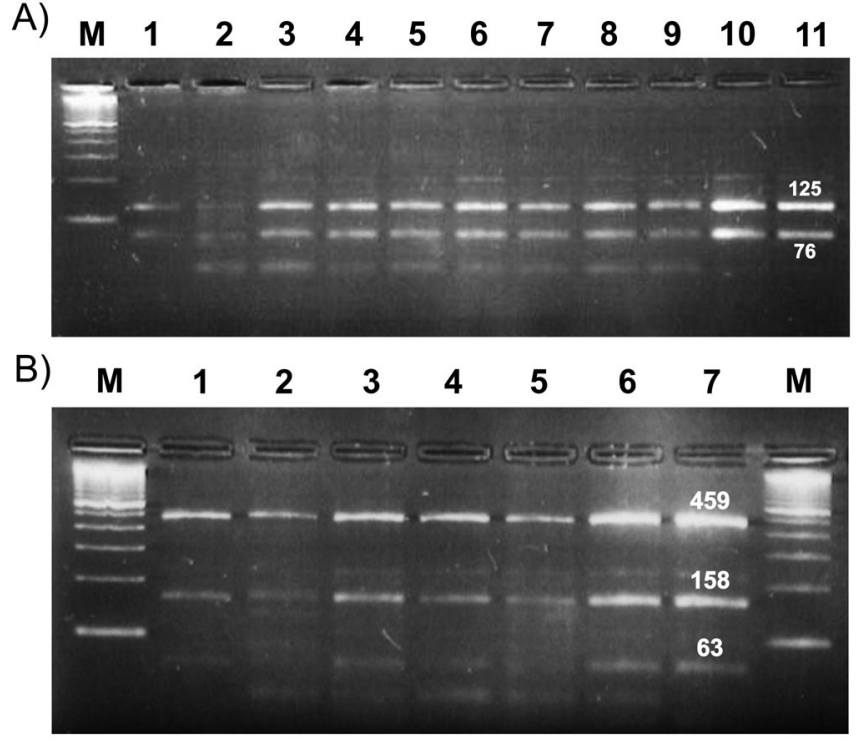

Fig. 5. RFLP analysis of Photobacterium damselae-specific PCR products from experimentally infected fishes. (A) BstU I digestion of fragment P.dam-1a_F-R. Lane M: size-marker 100 bp DNA Ladder (Invitrogen); Lanes 1 to 11: positive control (P. damselae subsp. piscicida strain NCIMB 2058 ${ }^{\mathrm{T}}$ ), D139a, Dl12b, Dl29b, Dl11c, Dl33c, Dl10d, Dl36d, Sa99, Sa130, and Sa131. (B) ECoR $V$ and BsmA $I$ digestion of fragment P.dam-5a_F-R. Lane M: size-marker 100 bp DNA ladder (Invitrogen); Lanes 1 to 7 : positive control $(P$. damselae subsp. piscicida strain NCIMB 2058 ${ }^{\mathrm{T}}$ ), Dl12b, Dl33c, Dl36d, Sa99d, Sa130d, and Sa131d

the presence of $P$. damselae subsp. piscicida. This evidence suggests that the pathogen might be identified at low titre from fishes not showing clinical signs of the disease.

Compared to routine cultural methods, the PCRRFLP approach proposed here requires the knowledge of a few simple molecular techniques. However, the reagents used are not expensive, and the experimental protocols are neither complicated nor excessively timeconsuming. The time needed to extract DNA from tissue samples, to carry out a PCR reaction, to perform a digestion with a single restriction enzyme, and to run samples in a normal agarose gel is less than 1 working day in total. Routine culture methods take days to provide a reliable answer. This makes a difference when trying to prevent an outbreak of fish pasteurellosis. The total cost for each sample is negligible, and the entire analytical process can be easily performed in parallel for tens of samples. For the above reasons, the method proposed here can be used in the routine screening for the presence of the pathogen.

Routine implementation of the PCR-RFLP tests presented in this paper, and especially the amplification and restriction of fragment P.dam-1a_F-R, on healthy fish might contribute toward an improved efficacy of prevention programs against fish pasteurellosis. 
Acknowledgements. We thank Dr. S. Adams, Institute of Aquaculture, University of Stirling, Scotland, who kindly provided many of the Photobacterium damselae subsp. piscicida strains used in this study. We thank also Serena Ferraresso for her excellent technical work, Mirko Volpin and Fabio Borghesan for their help with experimental infection, and Roberto Menegatti at Valle Ca' Zuliani for providing live animals.

\section{LITERATURE CITED}

Aoki T, Ikeda D, Katagiri T, Hirono I (1997) Rapid detection of the fish-pathogenic bacterium Pasteurella piscicida by Polymerase Chain Reaction targeting nucleotide sequences of the species-specific plasmid pZP1. Fish Pathol 32:143-151

Bakopoulos V, Volpatti D, Papanagiotou E, Richards R, Galeotti M, Adams A (1997) Development of an ELISA to detect Pasteurella piscicida in culture and in 'spiked' fish tissue. Aquaculture 156:359-366

Botella S, Pujalte MJ, Macián MC, Ferrús MA, Hernández J, Garay E (2002) Amplified fragment length polymorphism (AFLP) and biochemical typing of Photobacterium damselae subsp. damselae. J Appl Microbiol 193:681-688

Dalla Valle L, Zanella L, Belvedere P, Colombo L (2002) Use of random amplification to develop a PCR detection method for the causative agent of fish pasteurellosis, Photobacterium damselae subsp piscicida (Vibrionaceae). Aquaculture 207:187-202

Fouz B, Toranzo AE, Marco-Noales E, Amaro C (1998) Survival of fish-virulent strains of Photobacterium damselae subsp. damselae in seawater under starvation conditions. FEMS Microbiol Lett 168:181-186

Fouz B, Toranzo AE, Milan M, Amaro C (2000) Evidence that water transmits the disease caused by the fish pathogen Photobacterium damselae subsp damselae. J Appl Microbiol 88:531-535

Gauthier G, Lafay B, Ruimy R, Breittmayer V, Nicolas JL, Gauthier M, Christen R (1995) Small-subunit rRNA sequences and whole DNA relatedness concur for the reassignment of Pasteurella piscicida (Snieszko et al.). Jansen and Surgalla to the genus Photobacterium as Photobacterium damsela subsp. piscicida comb. nov. Int J Syst Bacteriol 45:139-144

Grayson TH, Cooper LF, Atienzar FA, Knowles MR, Gilpin ML (1999) Molecular differentiation of Renibacterium salmoninarum from worldwide locations. Appl Environ Microbiol 65:961-968

Kimura B, Hokimoto S, Takahashi H, Fujii T (2000) Photobacterium histaminum Okuzumi et al. 1994 is a later subjective synonym of Photobacterium damselae subsp. damselae (Love et al. 1981) Smith et al. 1991. Int J Syst Evol Microbiol 50:1339-1342

Editorial responsibility: Carey Cunningham, Aberdeen, UK
Kvitt H, Ucko M, Colorni A, Batargias C, Zlotkin A, Knibb W (2002) Photobacterium damselae ssp. piscicida: detection by direct amplification of 16S rRNA gene sequences and genotypic variation as determined by amplified fragment length polymorphism (AFLP). Dis Aquat Org 48:187-195

Magariños B, Romalde JL, Bandìn I, Fouz B, Toranzo AE (1992) Phenotypic, antigenic and molecular characterization of Pasteurella piscicida strains isolated from fish. Appl Environ Microbiol 58:3316-3322

Magariños B, Toranzo AE, Romalde JL (1996) Phenotypic and pathobiological characteristics of Pasteurella piscicida. Annu Rev Fish Dis 6:41-64

Magariños B, Osorio CR, Toranzo AE, Romalde JL (1997) Applicability of ribotyping for intraspecific classification and epidemiological studies of Photobacterium damselae subspecies piscicida. Syst Appl Microbiol 20:634-639

Magariños B, Toranzo AE, Barja JL, Romalde JL (2000) Existence of two geographically-linked clonal lineages in the bacterial fish pathogen Photobacterium damselae subsp. piscicida evidenced by random amplified polymorphic DNA analysis. Epidemiol Infect 125:213-219

Osorio CR, Collins MD, Toranzo AE, Barja JL, Romalde JL (1999) 16S rRNA gene sequence analysis of Photobacterium damselae and nested PCR method for rapid detection of the causative agent of fish pasteurellosis. Appl Environ Microbiol 65:2942-2946

Osorio CR, Toranzo AE, Romalde JL, Barja JL (2000) Multiplex PCR assay for ure $C$ and $16 \mathrm{~S}$ rRNA genes clearly discriminates between both subspecies of Photobacterium damselae. Dis Aquat Org 40:177-183

Pujalte MJ, Sitjà-Bobadilla A, Álvarez-Pellitero P, Garay E (2003) Carriage of potentially fish-pathogenic bacteria in Sparus aurata cultured in Mediterranean fish farms. Dis Aquat Org 54:119-126

Rajan PR, Lin JHY, Ho MS, Yang HL (2003) Simple and rapid detection of Photobacterium damselae ssp. piscicida by a PCR technique and plating method. J Appl Microbiol 95: $1375-1380$

Romalde JL, Magariños B, Lores F, Osorio CR, Toranzo AE (1999) Assessment of a magnetic bead-EIA based kit for rapid diagnosis of fish pasteurellosis. J Microbiol Methods $37: 147-154$

Snieszko SF, Bullock GL, Hollis E, Boone JG (1964) Pasteurella sp. from an epizootic of white perch (Roccus americanus) in Chesapeake Bay tidewater areas. J Bacteriol 88:1814-1815

Thyssen A, Grisez L, van Houdt R, Ollevier F (1998) Phenotypic characterization of the marine pathogen Photobacterium damselae subsp. piscicida. Int J Syst Bacteriol 48: $1145-1151$

Thyssen A, Van Eygen S, Hauben L, Goris J, Swings J, Ollevier F (2000) Application of AFLP for taxonomic and epidemiological studies of Photobacterium damselae subsp. piscicida. Int J Syst Evol Microbiol 50:1013-1019

Submitted: November 15, 2004; Accepted: February 24, 2005 Proofs received from author(s): June 13, 2005 